\title{
Estratégias singulares de agendamento: o caso do Greenpeace
}

\author{
Renata Borges Crispim*
}

\begin{abstract}
Resumo
A imprensa como esfera pública. O Terceiro Setor e a necessidade de visibilidade midiática. A entrada na esfera pública jornalística e o estabelecimento de estratégias de agendamento. $\mathrm{O}$ recurso à singularidade como estratégia de comunicação. $\mathrm{O}$ caso do Greenpeace e as estratégias elaboradas pela ONG para adentrar a esfera pública jornalística. Os resultados dos esforços de agendamento do Terceiro Setor. A singularidade como estratégia eficaz de agendamento. A imprensa e a valorização de novos atores sociais como atores aptos a ter voz ativa na arena pública do jornal.

Palavras-chave: agendamento, Terceiro Setor, jornalismo como esfera pública.
\end{abstract}

O papel que se imagina e se deseja para a imprensa brasileira é mais do que apenas a capacidade de seus profissionais assumirem a busca responsável por acontecimentos da realidade social que mereçam ser relatados nas páginas dos jornais. Em seu trabalho diário a imprensa passa a fazer parte de uma cadeia de influência que nasce na realidade social e é fonte desses acontecimentos, percorre a sociedade leitora do relato desses fatos e atinge a esfera política, que age a partir da percepção do que a sociedade debate e considera importante. É sabido que os debates realizados socialmente têm como tema, em grande parte, o que é retratado pela imprensa como importante e "digno de nota". Isso se deve, especialmente, ao fato de que é raro o

* Mestre em Comunicação pela Universidade de Brasília e Professora na Faculdade Sul-Americana em Goiânia.

Comun. Inf., v. 6, n. 2, p.75-86, jul./dez. 2003 
contato primário pelos integrantes do público com todos os acontecimentos noticiados diariamente. A dependência da sociedade com o trabalho da imprensa é reconhecida em função dessa impossibilidade, derivada diretamente da abrangência de eventos com os quais lidam os jornalistas.

Confiando na existência dessa cadeia de influência, diversos atores sociais se vêem às voltas com a necessidade de garantir a presença na esfera pública que se materializa na imprensa. Eé nesse momento que se pergunta: quais os critérios que normalmente são utilizados pelos profissionais do jornalismo na definição do que é ou não noticiável? Da mesma forma, quem são os atores sociais que precisam elaborar estratégias para garantir esse espaço?

A segunda questão motiva a averiguação a respeito da dificuldade encontrada por alguns atores sociais no acesso à imprensa. Os estudos realizados sobre os critérios de noticiabilidade demonstram a clara existência de uma facilidade maior de acesso aos jornais de atores sociais que detêm legitimidade e credibilidade já tradicionais na sociedade. Essa legitimidade é a mesma de que desfrutam políticos, artistas e outros personagens já conhecidos pelos leitores dos jornais. No entanto, outros atores sociais têm começado a fazer parte da cena político-social do Brasil e é em relação a eles que se questiona acerca da entrada na esfera pública jornalística, até porque esses são personagens são nascidos de iniciativas da chamada sociedade civil, como mostram as análises elaboradas por Nuria Cunill Grau ${ }^{1}$, autora venezuelana voltada para questões da administração pública e do Estado, cujo livro é amplamente fundamentado na obra habermasiana, e de Liszt Vieira² e Maria da Glória Gohn³.

A elaboração da hipótese da pesquisa realizada em Greenpeace: A Guerrilha Midiática como Estratégia ${ }^{4}$ se deu em virtude do entendimento de que a imprensa é uma realidade social especialmente próxima dos conceitos de esfera pública, elaborado por Habermas ${ }^{5}$,e de espaço público, de Wolton ${ }^{6}$. Por sua vez, a preocupação em criar estratégias de agendamento que garantam a presença de temas na esfera pública jornalística encontra reforço na hipótese de agenda-setting elaborada por McCombs e Shaw ${ }^{7}$, segundo a qual essas estratégias se justificam em função dos efeitos que a presença na mídia provoca: importância social dada ao tema. O estudo realizado é a descrição do processo que leva à elaboração de uma estratégia de agendamento específica, bem como do resultado dessa mesma estratégia. Tem-se

Comun. Inf., v. 6, n. 2, p.75-86, jul./dez. 2003 
como premissa que elaborar um esquema que pretensamente vai colocar um assunto no foco de visão da mídia deve passar pelo conhecimento das especificidades da linguagem normalmente utilizada pelos que obtém essa visão. Assim, os chamados valores-notícia e a singularidade, que é considerada o elemento central do jornalismo, segundo Adelmo Genro Filho ${ }^{8}$, são utilizados como base para essas estratégias de agendamento, como previsto na hipótese de pesquisa, que se completa com a idéia segundo a qual incrementar uma mensagem com esses valores-notícia e com essa singularidade é se apoiar numa estratégia que tem chances de ser altamente eficaz. Por isso se fez necessário, no estudo, verificar o resultado dessa estratégia, por meio de uma observação sobre o quanto que essa singularidade adicional promoveu a inserção de uma temática na esfera pública jornalística.

A descrição do processo pelo qual o agendamento é realizado passa pela importância de se buscar esse agendamento tendo como parâmetro o papel hoje atribuído à imprensa. Esse papel é analisado tanto em função da influência da imprensa na sociedade que a consome quanto no que se refere à sua posição em governos democráticos, para o qual contribuem as teorias de Habermas a respeito da democracia participativa. O problema principal da pesquisa, no entanto, define-se pelo quanto que um ator social, que não é buscado pelo olhar midiático e que também precisa dessa visibilidade, depende de uma série de estratégias para conseguir espaço na mídia.

Vários conceitos já foram desenvolvidos em relação à idéia de agendamento e o processo que normalmente é estabelecido na elaboração dessas estratégias. Os critérios comumente utilizados e o conhecimento deles são importantes porque é por meio deles que se tenta a adaptação da linguagem para uma que seja atraente ao olhar dos jornalistas.

O Greenpeace é a instituição escolhida para materializar o estudo a respeito do agendamento buscado por instituições do Terceiro Setor. A ONG há 11 anos está presente no Brasil, não obstante sua atuação mundial, ininterrupta desde 1971. O Greenpeace surgiu a partir de protestos realizados em outubro de 1969 contra uma série de testes nucleares realizados pelo governo dos Estados Unidos em Amchikta, nas Ilhas Aleutas, Pacífico Norte. Cerca de dez mil pessoas bloquearam um posto de fronteira entre os Estados Unidos e o Canadá, tentando impedir que os testes acontecessem. Entre eles, Jim Bohlen e Irving Stowe carregavam faixas pedindo: "Não faça onda", numa refe-

Comun. Inf., v. 6, n. 2, p.75-86, jul./dez. 2003 
rência aos maremotos causados pelos testes. A tentativa de impedimento não obteve sucesso e teve seu impacto desacreditado com o anúncio de que dois anos depois outros testes nucleares aconteceriam no mesmo local, também por iniciativa norte-americana.

Jim Bohlen, um ex-mergulhador nova-iorquino, havia combatido na Segunda Guerra Mundial e estava, no final da década de 1960, descontente com os rumos tomados pelo envolvimento norte-americano na Guerra do Vietnã. O descontentamento o levou para Vancouver, Canadá, onde se engajou em movimentos antiguerra, que o levariam a conhecer o advogado Irving Stowe, já atuante pacifista e ecologista. Juntos, eles formaram o comitê Não faça Onda, que objetivava lutar contra os testes nucleares norte-americanos. O comitê pode ser considerado o embrião do que hoje se conhece como Greenpeace, instituição que nasce a partir do alargamento dos interesses do Não faça onda. Esse alargamento se resume à definição de que a organização recém-fundada trataria, especialmente, de dois temas: a luta contra a degradação ambiental e o pacifismo. $\mathrm{Ou}$, em outras palavras, o "verde" e a "paz" que, em inglês, levaram à mudança do nome da instituição para o que é hoje mundialmente conhecido. A decisão de modificar o nome de Não faça onda para Greenpeace é, inclusive, um indicativo de boa parte dos objetivos a que a ONG se dedicaria anos mais tarde: chamar a atenção da opinião pública para os perigos da degradação ambiental, objetivo que depende, em grande parte, do acesso à imprensa.

Esse acesso buscado pelo Greenpeace foi analisado por meio dos releases (considerados pela ONG o principal instrumento de agendamento) relativos às ações diretas, a partir dos parâmetros $\mathrm{e}$ categorias definidos por Adelmo Genro Filho como intrínsecos à prática jornalística (a singularidade, a particularidade e a universalidade). As matérias publicadas nos cinco jornais analisados (Folha de S. Paulo, O Estado de S. Paulo, O Globo, Jornal do Brasil e Correio Braziliense) são vistas segundo os mesmos parâmetros, numa tentativa clara de verificar se há a permanência e o predomínio desses valores mesmo quando o tema tratado é de claro interesse público, como é o caso da questão ambiental.

A pesquisa busca compreender a relação estabelecida entre esses novos atores sociais brasileiros e a imprensa, capaz de dar legitimidade e credibilidade a iniciativas de cunho social e político. A atualidade do avanço de iniciativas da sociedade civil e a atuação constante e

Comun. Inf., v. 6, n. 2, p.75-86, jul./dez. 2003 
internacionalmente reconhecida do Greenpeace tornam necessário o entendimento de como os jornais brasileiros valorizam e focam a entidade, que é, no mínimo, legítima representante do Terceiro Setor brasileiro. Se autodenominando como "guerreiros do arco-íris", o Greenpeace tem sua atuação fundada na idéia segundo a qual é de sua responsabilidade chamar a atenção para a questão ambiental em todos os países em que trabalha, o que em muito justifica a escolha da ONG como estudo de caso.

O estudo foi realizado em variadas etapas, que passam pela ida à sede da organização na cidade de São Paulo, a fim de compreender como se dava o estabelecimento das estratégias de comunicação da ONG, a análise do principal instrumento dessas estratégias-os releases - e o levantamento e análise do resultado do esforço do Greenpeace - as matérias publicadas com referência às ações citadas nos releases.

A pesquisa teve como hipótese principal a premissa de que a adição de singularidade era uma estratégia de agendamento eficaz no estímulo à atenção midiática a uma questão.

Partiu-se do pressuposto de que recorrer a esse tipo de estratégia era uma forma de garantir que a imprensa olharia com atenção a um tema de interesse público, especialmente quando ele estava sendo trazido à arena social e política por um ator social que não tinha tradição de entrada nessa mesma arera, quer seja por carência de legitimidade e autoridade reconhecida, quer seja pelas dificuldades impostas a esse acesso. Fica claro, portanto, que a hipótese da pesquisa já aponta para um possível paradoxo na prática jornalística da forma que esta é realizada atualmente, já que freqüentemente é reafirmada a função pública da imprensa. Essa função está materializada na atenção à maior quantidade possível de opiniões acerca de determinada questão, sintetizadas na idéia de pluralismo, tão comum nos discursos sobre o trabalho e papel da imprensa.

A fim de verificar como atualmente funciona esse tão aclamado pluralismo na imprensa brasileira, estabeleceu-se como problema de pesquisa a atenção dada a um ator social que só há pouco tempo figura como falante na esfera política no Brasil. Talvez representando todo um conjunto desses atores, o Greenpeace foi escolhido como a instituição que melhor poderia exemplificar as dificuldades envolvidas no acesso à esfera pública jornalística, bem como poderia demonstrar a eficácia da estratégia aqui estabelecida como provável para assegurar essa entrada.

Comun. Inf., v. 6, n. 2, p.75-86, jul./dez. 2003 
A elaboração da hipótese surgiu da atenção aos valores comumente estipulados e obedecidos pela esfera jornalística, no entendimento do que é ou não considerado noticiável. Como afirmado, todos os dias diversos acontecimentos são colocados diante daqueles que definem o que vai ou não figurar nas páginas dos jornais como "os últimos e mais importantes acontecimentos das últimas 24 horas no mundo". Além do questionamento acerca do quanto os acontecimentos que se colocam para avaliação dos jornalistas são efetivamente uma amostra real dos "últimos acontecimentos do mundo", cabe perguntar o que é utilizado como critério de escolha entre os fatos que, quaisquer motivos estão dispostos para "escolha". Inclui-se nesse processo não apenas aqueles fatos que são vistos pelos jornalistas a partir de um movimento destes em direção à parte da realidade social, mas também aqueles que lhes são apresentados mediante um movimento que parte de quem quer ser visto. Há, como se vê, uma caminhada em direção ao local em que socialmente se localizam os jornalistas. Eesse movimento foi estudado buscando-se um entendimento sobre até que ponto o conhecimento dos critérios normalmente utilizados pela esfera pública jornalística influi na elaboração do caminho trilhado pelos atores sociais que dele dependem para serem olhados com atenção pelos jornalistas.

Os critérios ou, como aqui foram chamados, valores-notícia que se supõe conhecidos pelos atores sociais que dependem da elaboração de estratégias de agendamento midiático e aqui utilizados como parâmetros para a pesquisa - são aqueles apresentados por Adriano Duarte Rodrigues ${ }^{9}$ (proximidade geográfica, quebra da rotina, etc). Contribui também para a elaboração dessas estratégias o que Adelmo Genro Filho ${ }^{10}$ chama de singularidade ou, nos dizeres do autor, o elemento central do jornalismo. Esse elemento provém do primeiro contato do jornalista com o fato a ser posteriormente relatado.

Foram esses os parâmetros utilizados na pesquisa sobre o processo que leva uma mensagem do seu emissor inicial (no caso, o Greenpeace) até o receptor final (a sociedade), que é atingido pela intermediação midiática dos jornais. As mensagens elaboradas pelo Greenpeace foram analisadas a partir desses parâmetros, assim como as mensagens efetivamente publicadas e que têm origem no estímulo da ONG para essa publicação.

$\mathrm{O}$ que foi percebido é que, no tocante às mensagens elaboradas pelo Greenpeace, a hipótese se confirma: elas realmente são produzi-

Comun. Inf., v. 6, n. 2, p.75-86, jul./dez. 2003 
das de uma forma que busca adequá-las à premissa de Adelmo de que o singular é a categoria central do jornalismo. Isso fica evidente na percepção de que todos os releases (principal instrumento de agendamento utilizado pela ONG) são elaborados de forma a apresentar mais do que apenas o caráter singular, mas um elemento singularizado adicional, que busca tornar o evento ainda mais noticiável do que é. Esses eventos são basicamente as ações diretas conhecidas no mundo todo como a principal forma de atuação do Greenpeace. Elas são manifestações nas quais a entidade busca chamar a atenção da sociedade para uma determinada situação de perigo ambiental. Elaboradas de forma a criar um simbolismo para a mensagem do Greenpeace, as ações diretas são relatadas pela ONG para a imprensa de uma maneira que não apenas descreve a encenação simbólica do protesto, mas também apresenta todas as conexões necessárias, segundo Adelmo, para a elaboração de uma notícia capaz de produzir um significado social suficiente para a geração de discussões a respeito do tema da mensagem. A singularidade adicionada pelo Greenpeace está presente, por exemplo, quando a entidade escolhe promover um jogo de futebol com ativistas vestidos com camisas da Inglaterra e Japão contra outros representando a própria instituição, numa encenação que sintetiza a situação que de fato estava acontecendo: os dois países estavam sendo confrontados pela entidade por planejarem um carregamento de plutônio que poderia causar grave dano ambiental. A singularidade adicional, como se vê, está na forma que o Greenpeace escolhe para tornar sua mensagem noticiável. Isso não impede, no entanto, que a instituição se preocupe em contextualizar o evento que promove, numa clara tentativa de que a cobertura conseguida não se paute apenas por essa encenação que, se garante uma entrada na esfera pública jornalística, não ajuda a promover uma mensagem corretamente contextualizada.

A análise das matérias publicadas revelou que a singularidade presente nos releases do Greenpeace realmente é capaz de provocar o acesso da mensagem da entidade na esfera pública jornalística, o que acaba por confirmar a hipótese. A adição de singularidade é efetivamente uma estratégia de agendamento eficaz. O que não significa, infelizmente, que a atenção a esse elemento da mensagem do Greenpeace garanta a mesma atenção aos outros elementos, mesmo que eles estejam presentes nos releases. A particularidade e a universalidade, elementos também descritos por Adelmo e responsáveis pela

Comun. Inf., v. 6, n. 2, p.75-86, jul./dez. 2003 
contextualização da notícia com outros fatos do mundo social e com a história relativa àquele tema, mesmo presentes nos releases elaborados pelo Greenpeace não foram vistas com a mesma freqüência que a singularidade.

Esse resultado aponta, em relação ao olhar da imprensa para os novos atores sociais hoje atuantes no Brasil, para um desprestígio que só é relevado quando há uma clara obediência aos critérios mais comuns de noticiabilidade, como a proximidade geográfica ou a presença da singularidade e de uma singularidade adicionada à mensagem com o propósito específico de chamar a atenção da imprensa. Mais do que isso, o que se percebe é que mesmo quando a atenção midiática é obtida por meio dessa obediência, isso não necessariamente implica uma atenção a outros fatores igualmente importantes na produção de notícias socialmente responsáveis. Essa pequena atenção, por sua vez, implica na existência de um ciclo no qual valores-notícia como a proximidade geográfica e a singularidade por vezes extremada não deixam de ser critérios fundamentais para o agendamento, a despeito da importância pública do tema tratado, ou do papel social assumido e representado pelo ator falante. $\mathrm{O}$ fato de o Greenpeace ser um ator social genuinamente nascido e mantido por iniciativa da sociedade civil e de tratar de um tema tão publicamente interessante como o meio ambiente é significativo, já que nem mesmo essas fortes características do tema e de quem fala foram suficientes para garantir a noticiabilidade de aspectos tão fundamentais como a particularidade e a universalidade. Negando atenção a esses aspectos, verifica-se a negação ao tratamento da questão ambiental relatada pelo Greenpeace de uma forma mais profunda e fundamentada nas relações que cada ação direta estabelece com o tema e com outros acontecimentos, recentes ou não.

Outra conclusão pode ser tirada do resultado alcançado, por meio da análise realizada, em relação à posição do Greenpeace diante da imprensa. Tendo atuado como protagonista das matérias nas quais as ações diretas foram relatadas, verifica-se o predomínio de uma cobertura que focaliza mais o autor da mensagem do que o seu conteúdo, assim como há um predomínio claro da atenção à forma escolhida pela ONG para transmitir sua mensagem, em prejuízo de sua profundidade. A singularidade se manifesta na observação do que está sendo dito, por quem e como. As relações do que é dito com outras mensagens, do mesmo autor ou não, recentes ou não, bem como a conexão

Comun. Inf., v. 6, n. 2, p.75-86, jul./dez. 2003 
do tema da mensagem com aspectos da vida social, em relação aos quais a sociedade pode debater e deliberar, estão presentes nos releases elaborados e constituem o que é chamado de particularidade e universalidade. No entanto, esses aspectos não obtiveram a mesma visibilidade da imprensa, o que aponta para a manutenção da ONG apenas como ator social capaz de destacar questões públicas, mas com freqüência sua voz não é considerada pertinente para a fala a respeito dessas questões.

Se for possível elaborar algum provável desenvolvimento em relação à situação atual da imprensa brasileira e as conclusões aqui encontradas, este implica na consideração de que uma imprensa socialmente responsável e atenta às modificações pelas quais passou a sociedade brasileira nos últimos anos ainda não se faz presente no Brasil. Os cinco maiores jornais do país, quando em contato com um ator social que é legítimo representante dos novos atores que passaram a integrar a arena político-social do país nas últimas décadas, não demonstram interesse em garantir uma atenção a esse ator social condizente com a posição que este têm no atual cenário brasileiro. A situação se agrava quando se considera a função social da imprensa, tão fortemente defendida pelos próprios jornalistas. Se a obediência a esse papel passa pela atenção a todas as vozes socialmente responsáveis por temas de interesse público (como prevê a ligação entre a imprensa e a esfera pública habermasiana, ou o espaço público de Wolton), fica aqui o registro de uma dessas vozes fracamente ouvidas e que, apesar disso, continua falando de forma a manter a busca por um espaço que a focalize de forma completa e profunda, capaz de apresentar à sociedade sua real visão de mundo.

\section{Abstract}

The press in the public sphere. The Third Sector and the need for media visibility. The entrance in the journalistic public sphere and the establishment of strategies of agenda setting. Singularity as a communication strategy resource. The case of Greenpeace and the strategies used by such NGO to enter the journalistic public sphere. The results of the efforts of agenda setting by the Third Sector. Singularity as an efficient agenda setting strategy. The press and the value of new social elements as elements which are apt to take an active role in the public arena of the newspaper. sphere.

Key words: strategies of agenda setting, Third Sector, journalistic public

Comun. Inf., v. 6, n. 2, p.75-86, jul./dez. 2003 


\section{Notas e referências}

1. GRAU, N. C. Repensando o público através da sociedade: novas formas de gestão pública e representação social. Rio de Janeiro: Revan, Brasília: ENAP, 1998.

2. VIEIRA, L. Cidadania e globalização. Rio de Janeiro: Record, 2001.

3. GOHN, M. G. Mídia, terceiro setor e MST: impactos sobre o futuro das cidades e do campo. Petrópolis: Vozes, 2000.

4. Dissertação de mestrado elaborada pela autora e defendida em sessão pública em 14/07/2003, na Universidade de Brasília.

5. HABERMAS, J. Mudança estrutural da esfera pública. Rio de Janeiro: Tempo Brasileiro, 1984.

6. WOLTON, D. Penser Ia communication. Paris: Flammarion, 1997.

7. McCOMBS, M.; SHAW, D. The agenda setting function of mass media. In: Public Opinion Quaterly. [S.1.], vl. 36, 1972.

8. GENRO, A. F. O segredo da pirâmide: para uma teoria marxista do jornalismo. Porto Alegre: Tchê, 1987.

9. RODRIGUES, A. D. O acontecimento. In: TRAQUINA, N. Op. cit.

10. GENRO, A. F. Op. cit.

\section{Referências}

ARENDT, H. A condição humana. 10. ed. Rio de Janeiro: Forense Universitária, 2001.

AVRITZER, L. A moralidade da democracia. São Paulo: Perspectiva, 1996.

BREED, W. Controlo social na redação. In: TRAQUINA, N. (Org.). Jornalismo, questões, teorias e estórias. 2. ed. Lisboa: Vega, 1999.

CALHOUN, C. Habermas and the public sphere. Cambridge (MA): MIT Press, 1992.

CATALÃO, T. T. Para que serve um jornal? Correio Braziliense, Brasília, 19 set. 1999.

DAGNINO, E. Anos 90: política e sociedade no Brasil. São Paulo: Brasiliense, 1994.

DAHL, R. Preface to democratic theory. Chicago: University of Chicago Press, 1956.

DEFLEUR, M. L.; BALL-ROKEACH, S. Teorias da comunicação de massa. Rio de Janeiro: Jorge Zahar, 1993.

ENTMAN, R. M. Framing: toward clarification of a fractured paradigm. Journal of Communication, [S.1.], v. 43, 1993, pp.51-8.

FERNANDES, R. Privado porém público: o terceiro setor na América Latina. 2. ed. Rio de Janeiro: Relume Dumará, 1994.

FREITAG, B. A questão da moralidade: da razão prática de Kant à ética discursiva de Habermas. In: Tempo social. São Paulo, tomo 1, n. 2, 1989.

GAMSON, W. Talking politics. [S.1.]: Cambridge University Press, 1992.

GENRO, A. F. O segredo da pirâmide: para uma teoria marxista do jornalismo. Porto Alegre: Tchê, 1987.

Comun. Inf., v. 6, n. 2, p.75-86, jul./dez. 2003 
GITLIN, T. The whole world is watching. Berkeley: University of California Press, 1980.

GOHN, M. G. Mídia, terceiro setor e MST: impactos sobre o futuro das cidades e do campo. Petrópolis: Vozes, 2000.

GRAU, N. C. Repensando o público através da sociedade: novas formas de gestão pública e representação social. Rio de Janeiro: Revan, 1998.

GRUPPI, L. Tudo começou com Maquiavel: as concepções de Estado em Marx, Engels, Lênin e Gramsci. Porto Alegre: L\&PM Editores, 1986.

HABERMAS, J. Mudança estrutural da esfera pública. Rio de Janeiro: Tempo Brasileiro, 1984.

. Further reflections on the public sphere, em Craig Calhoun. (Org.).

Habermas and the public sphere. Cambridge (MA): MIT Press, 1992.

Direito e democracia: entre faticidade e validade. Rio de Janeiro: Tempo Brasileiro, v. 2, 1997.

. Theory of communicative action. Boston: Beacon Press, 1984.

KUNCZIK, M. Conceitos de Jornalismo. São Paulo: Edusp, 1997.

LAURELL, A. C. (Org.). Estado e políticas sociais no neoliberalismo. 2. ed. São Paulo: Cortez, 1997.

MARCONDES, C. F. O capital da notícia: jornalismo como produção social de segunda natureza. São Paulo: Ática, 1986.

MATTELART, A. M. Histórias das teorias da comunicação. São Paulo: Loyola, 1999.

McCOMBS, M.; SHAW, D. The agenda setting function of mass media. In: Public Opinion Quaterly, [S.1.: s.n.], v. 36, 1972.

MEKSENAS, P. Cidadania, poder e comunicação. São Paulo: Cortez Editora, 2002.

MELO, J. M. Comunicação e modernidade. São Paulo: Loyola, 1991.

MONTORO, T. S. (Org.). Comunicação, cultura, cidadania e mobilização social. Brasília: UnB, 1997.

MIĖGE, B. O pensamento comunicacional. Petrópolis: Vożes, 2000.

MURARO, H. Políticos, periodistas y ciudadanos. Buenos Aires: Fondo de Cultura Econômica, 1997.

RODRIGUES, A. D. O acontecimento. In: TRAQUINA, N. Jornalismo: questões, teorias e estórias. 2. ed. Lisboa: Vega, 1999.

RUBIM, A. A. C. Comunicação e política. São Paulo: Hacker Editores, 2000.

SALASSIE, A. A tangibilidade do release e seus efeitos mobilizadores. In: MONTORO, T. (Org.). Comunicação, cultura, cidadania e mobilização social. Brasília: UnB, 1997.

SANTOS, B. S. Pela mão de Alice: o social e o político na pós-modernidade. 8. ed. São Paulo: Cortez, 2001.

SCHUMPETER, J. Capitalismo, socialismo e democracia. Rio de Janeiro: Fundo de Cultura, 1961.

SILVA, L. M. A imprensa livre é o coração do espaço público. Correio Braziliense, Brasília, 25 out. 2002.

SODRÉ, N. W. História da imprensa no Brasil. 4. ed. Rio de Janeiro: Mauad, 1999.

Comun. Inf., v. 6, n. 2, p.75-86, jul./dez. 2003 
TAVOLARO, S. B. F. Movimento ambientalista e modernidade: sociabilidade, risco e moral. São Paulo: Annablume, 2001.

TEIJEIRO, C. A. Fundamentos teóricos del periodismo público. Buenos Aires: Universidad Austral, 1999.

TRAQUINA, N. (Org.). Jornalismo: questões, teorias e estórias. Lisboa: Vega, 1995.

2001.

. O estudo do jornalismo no século XX. São Paulo: Editora Unisinos,

. As notícias. In: TRAQUINA, N. Jornalismo: questões, teorias e estórias. Lisboa: Vega, 1995.

VIEIRA, L. Cidadania e globalização. Rio de Janeiro: Record, 1997.

WEBER, M. Economia e sociedade. Brasília: UnB, 1991.

WOLF, M. Teorias da comunicação. Lisboa: Presença, 1995.

WOLTON, D. Penser la communication. Paris: Flammarion, 1997.

Comun. Inf., v. 6, n. 2, p.75-86, jul./dez. 2003 